\title{
Öljykasvien GM-lajikkeiden jääntikasviriskit
}

Katri Pahkala ${ }^{1)}$, Pirjo Peltonen-Sainio ${ }^{1)}$, Leo Mustonen ${ }^{1)}$ ja Hannu Mikkola ${ }^{2)}$

${ }^{1)}$ MTT, Kasvintuotannon tutkimus, E-talo, 31600 Jokioinen, etunimi.sukunimi@mtt.fi

${ }^{2)}$ Helsingin yliopisto, Agroteknologian laitos, PL 28, 00014 Helsingin yliopisto, hannu.mikkola@helsinki.fi

\section{Tiivistelmä}

Useilla kasveilla osa kylvetyistä siemenistä voi jäädä lepotilaan tai osa korjattavasta sadosta jää tappioina peltoon. Tällainen jääntimateriaali voi säilyä talven yli elinkykyisenä ja tuottaa lisääntymiskykyisiä kasveja seuraavina vuosina, jos olosuhteet ovat suotuisat. Erityisesti tämä ominaisuus liitetään rypsiin ja rapsiin, joiden on havaittu ilmaantuvan pelloille jääntikasveina useiden vuosien ajan niiden viljelyn loppumisen jälkeen.

MTT:n kasvintuotannon tutkimuksessa selvitettiin jääntikasveista aiheutuvien riskien todennäköisyyttä Suomen kasvuoloissa rapsilla, rypsillä ja perunalla. Tutkimus kuului osana isompaan tutkimuskokonaisuuteen "GM-lajikkeiden geeniaineksen siirtyminen Suomen kasvuoloissa: menetelmät todentamiseen ja riskien hallintaan”. Tutkimus toteutettiin kenttäkokeina 2004 - 2007 välisenä aikana Jokioisilla käyttäen kaupallisia, perinteisellä tavalla jalostettuja lajikkeita. Öljykasvitutkimuksissa keskityttiin pääasiassa rapsiin. Tutkimuskohteina olivat alkutuotannon vaiheet, joissa ei-toivotun geeniaineksen siirtyminen siemenen välityksellä olisi mahdollista eli kylvö, siemenen kypsyminen ja puinti. Jääntisiementen elinvoimaa selvitettiin kolmen vuoden ajan kesannolla, suorakylvössä ja perinteisessä kyntöviljelyssä Lisäksi tutkittiin jääntisiementen säilymistä maassa ja jääntikasvien kemiallista hävittämistä.

Kylvön yhteydessä keväällä osa rapsin siemenistä jäi taimettumatta. Maanpinnalle jääneistä siemenistä vain $40 \%$ taimettui. Ongelmana olivat myös syvemmälle kuin $5 \mathrm{~cm}$ :iin joutuvat siemenet, joista osa jäi lepotilaan ja taimettui myöhemmin. Puintitappiot olivat öljykasveilla merkittävin jääntikasvien lähde. Puinnin yhteydessä rapsinsiementä joutui peltoon pelkästään kela-, kohlin- ja seulastotappioina noin $3 \%$ ja rypsinsiementä 2,6 \% puidusta sadosta. Pöytätappiot mukaan lukien korjuutappion koko määrä oli rapsilla 5,2 \% (119 kg) ja rypsillä 4,5 \% (86 kg) siemensadosta. Verrattaessa eri viljelymenetelmiä jääntikasveja löytyi vähiten tavanomaisessa kyntöviljelyssä. Rypsin ja rapsin jääntikasvit voitiin hävittää viljasta nykyisillä herbisibivalmisteilla. Edellytyksenä oli, että mahdolliset jääntikasvit olivat jo taimettuneet käsittelyhetkellä. Vahva viljakasvusto ja tuholaiset heikensivät myös öljykasvitaimia käsittelemättömissä kasvustoissa. Herbisidikäsittelyn uusiminen myöhäisemmässä vaiheessa voi varmistaa myöhään itävien öljykasvien tuhoutumisen.

Rapsin ja rypsin siementen variseminen puinnin yhteydessä, säilyminen maassa itävänä useita vuosia ja lajikkeiden dormanssiherkkyys voivat johtaa ei-toivotun geeniaineksen siirtymiseen, jos GMlajikkeita aletaan viljellä rypsin pääviljelyalueilla.

\section{Asiasanat}

rapsi, rypsi, Brassica, jääntikasvit, viljelytekniikka, dormanssi, taimettuminen, herbisidikestävyys, puintitappiot 


\section{Johdanto}

Useilla kasveilla osa kylvetyistä siemenistä voi jäädä lepotilaan tai osa korjattavasta sadosta varisee ennen korjuuta tai jää tappioina peltoon korjuun yhteydessä. Jääntimateriaali voi säilyä talven yli elinkykyisenä ja tuottaa lisääntymiskykyisiä kasveja seuraavina vuosina, jos olosuhteet ovat suotuisat. Ongelma on tuttu varsinkin rypsin ja rapsin viljelyssä, kun öljykasveja ilmaantuu pelloille useiden vuosien ajan vielä viljelyn loppumisen jälkeen. Rypsi ja sen ristikukkaiset sukulaisrikkakasvit kuuluvat jo viljapeltojen rikkakasvilajistoon (Salonen et al., 2001). Luonnossa rypsiä tavataan satunnaisesti tienvarsilla ja lastauspaikoilla. Rapsi näyttäisi olevan huomattavasti harvinaisempi (Hämet-Ahti et al., 1998). Tämän rikkakasviongelman merkitys saattaa muuttua, jos Suomessa aletaan viljellä rapsin GM-lajikkeita. Muunneltua geeniainesta ei saisi siirtyä tavanomaisesti tai luonnonmukaisesti viljeltyyn GM-vapaaseen materiaaliin missään tuotantoprosessin vaiheessa. Varteenotettavan riskin muodostavat jääntisiemenistä kasvavat, tavanomaiseen materiaaliin sekoittuvat ja/tai edelleen siitepölylähteenä toimivat kasvit. Sekoittumista voi tapahtua myös siemeneriä siirreltäessä ja koneiden mukana. Käytännön viljelyssä rapsin siemeniä varisee ennen korjuuta ja korjuun yhteydessä maahan. Pahkalan ja Sankarin (2001) tutkimusten mukaan ennen korjuuta rapsin siemeniä varisee $0,1-1 \%$ ja rypsiä $0,1-0,6 \%$ sadosta. Jos olosuhteet ovat suotuisia, suuri osa siemenistä itää välittömästi, mutta osa vasta seuraavina vuosina.

Tutkimuksemme kohteina olivat ne viljelyn vaiheet, joissa ei-toivottua geeniainesta saattaisi siirtyä jääntisiementen välityksellä eli kylvö, siemenen kypsyminen ja puinti. Lisäksi tutkittiin jääntisiementen säilymistä maassa ja jääntikasvien kemiallista hävittämistä. Tutkimuksessa käytettiin kaupallisia öljykasvilajikkeita, jotka eivät sisältäneet geenimuunneltua ainesta. Oletuksena oli, että transgeeniset lajikkeet eivät eroa siementen säilymisessä ja jääntikasvien tuotannossa perinteisesti jalostetuista lajikkeista (Crawley et al., 1993).

\section{Aineisto ja menetelmät}

Jääntisiemenriskiä kylvön yhteydessä selvitettiin Jokioisille 17.5.2005 perustetussa tutkimuksessa. Rapsin siementä (lajike Wildcat) kylvettiin 100 kappaleen erinä 0, 2,5, 5, 10 ja 20 cm:n syvyyteen 25 x 25 cm:n ruutuihin. Kokeessa oli neljä kerrannetta. Taimet laskettiin aluksi kolme kertaa viikossa ja taimettumisen loppuvaiheessa kerran viikossa.

Viljelymenetelmän vaikutusta rapsin jääntisiementen elinvoimaan tutkittiin vuosina 2004 -2007. 4.10.2004 kylvettiin $63 \mathrm{~kg}$ ha vastapuitua rapsia (lajike Wildcat) viljan sänkeen 37 m x 50 m koealueelle. Koejärjestelyissä käytettiin osaruutumallia, jossa pääruutuna oli viljelymenetelmä (kesanto, suorakylvö, kyntöviljely) ja osaruutuna herbisidikäsittely (ei käsittelyä, viljelynmukainen käsittely). Ruudun koko oli 2,5 x 10 m. Kokeessa oli neljä kerrannetta. Kesannolla ei tehty viljelytoimenpiteitä. Suorakylvö tehtiin keväällä (ohra 2005, vehnä 2006, ohra 2007). Kyntöviljelykoejäsen kynnettiin ensimmäisen kerran 11.11.2004. Kynnetyt alueet muokattiin keväällä ja niihin kylvettiin kylvölannoittimella samaa kevätviljaa kuin suorakylvössäkin. Toimenpiteet toistettiin kolmena vuonna. Herbisidikäsittely tehtiin 29.10. 2004 glyfosaatilla. Seuraavina vuosina kevätviljakoejäsenten rikkakasviruiskutukset tehtiin normaaliin käsittelyaikaan fenoksihappoherbisidillä ja kesannolla glyfosaatilla. Vuonna 2004 taimettuneet rapsit laskettiin ennen ruiskutusta ja toisen kerran juuri ennen kyntöä. Laskenta tehtiin ruuduittain kahdesta 0,25 $\mathrm{m}^{2}$ suuruisesta ympyrästä. Seuraavina vuosina taimet laskettiin kerran viikossa kasvukauden alusta lähtien aina syyskyntöön asti. Taimet poistettiin laskennan jälkeen.

Rypsin ja rapsin kela-, seulasto- ja kohlintappio mitattiin puinnin yhteydessä ISO 8210 menetelmällä (rypsi 7.9.2005 ja rapsi 16.9.2005) kuudesta 25 metrin kaistasta. Puimurin pöytätappio mitattiin samoilta alueilta käyttämällä metallisia keräyskaukaloita. Lisäksi mitattiin öljykasvien siemen- ja varsisato. Koe tehtiin Jokioisten kartanoiden käytännön viljelyksillä.

Jääntisiementen elinvoimaa tutkittiin hautaamalla 100 siemenen eriä polyeteeniverkosta valmistetuissa $5 \mathrm{~cm}$ x $15 \mathrm{~cm}$ pusseissa 0,10 ja $20 \mathrm{~cm}$ :n syvyyteen maahan neljään kerranteeseen 5.10.2004. Siemeneriä idätettiin keväisin ja syksyisin neljänä vuonna Jacobsenin altaassa. Jokaista idätyskertaa varten oli varattu omat siemenerät.

Rypsin (lajike Hohto) ja rapsin (lajike Marie) jääntikasvien kemiallista hävittämistä tutkittiin kesällä 2007. Molempia öljykasveja kylvettiin puhtaana kasvustona ja viljan kanssa kaistoina kolmeen kerranteeseen. Roope-kauraa kylvettiin 200 kg/ha (7.5.). Rapsia kylvettiin 6,2 kg/ha ja rypsiä 6 kg/ha (11.5.). Kolmen herbisidikäsittelyn vaikutusta öljykasveihin verrattiin käsittelemättömään koejäseneen. Torjunta-ainevalmisteet olivat: Ariane S (tehoaine MCPA+fluoroksipyyri+klopyralidi), Express 
50T+Hedonal MCPA (tehoaine tribenuroni-metyyli+MCPA), Hedonal MCPA (tehoaine MCPA). Herbisidikäsittely tehtiin 4.6. kauran versomisen alussa kevätviljoille suositellulla valmistemäärällä sekä öljykasveille että vilja+öljykasvi -koejäsenille. Ruiskutuksen jälkeen havainnoitiin öljykasvin, kauran ja rikkakasvien peittävyyttä ja öljykasvien vioittumisen etenemistä. Kauran kypsymisen aikaan 10.9. otetuista näytteistä laskettiin öljykasvien lukumäärä ja mitattiin niiden biomassa ja erikseen siementen lukumäärä ja paino $0,125 \mathrm{~m}^{2}$ alalta.

\section{Tulokset ja tulosten tarkastelu}

Kylvön yhteydessä osa siemenistä jäi taimettumatta. Ongelmana olivat erityisesti maanpinnalle jäävät ja yli 5 cm syvyyteen joutuvat siemenet (Kuva 1). Rypsi taimettuu nopeimmin matalaan kylvettynä edellyttäen kuitenkin, että siemen ei pääse kuivumaan missään vaiheessa. Tämä on todettu aiemmissakin tutkimuksissa (Pahkala, 2003). Suotuisat kylvöolosuhteet (lämpötila, kosteus, maanrakenne) ja sopiva kylvösyvyys edistävät itämistä. Kun siemen joutuu liian syvälle, valon puute voi aiheuttaa lepotilan (Woolley \& Stoller, 1978), joka laukeaa vasta siemenen joutuessa uudelleen lähelle maanpintaa, jos muut olosuhteet itämiselle ovat suotuisat. Taimettumatta jääneet, lepotilassa olevat siemenet saattavat siirtää muunneltua geeniainesta, jos taimettuminen siirtyy esimerkiksi seuraavaan vuoteen.

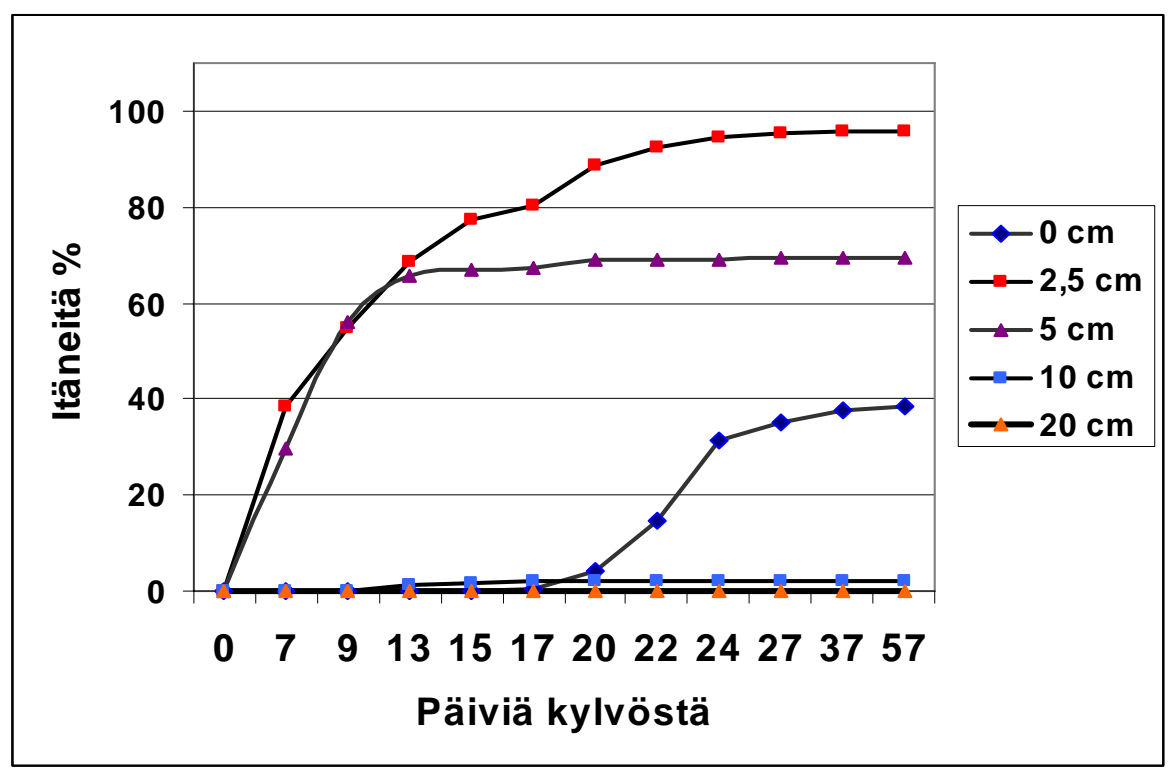

Kuva 1. Kylvösyvyyden vaikutus rapsin itämiseen. Jokioinen, 2005.

Toinen ja selvästi suurempi jääntisiementen lähde olivat puinnin yhteydessä varisevat öljykasvien siemenet. Puinnin yhteydessä siementä joutui peltoon pelkästään kela-, kohlin- ja seulastotappioina rapsilla noin $3 \%$ ja rypsillä 2,6 \% puidusta sadosta. Pöytätappiot mukaan lukien korjuutappion koko määrä oli rypsillä 4,5 \% ja rapsilla 5,2 \% siemensadosta. Rypsin siemensato puintikokeessa oli $1.9 \mathrm{t}_{\mathrm{ka}} / \mathrm{ha} \mathrm{ja}$ varsisato 2,7 $\mathrm{t}_{\mathrm{ka}} / \mathrm{ha}$. Rapsin siemensato oli 2,3 $\mathrm{t}_{\mathrm{ka}} /$ ha ja varsisato $3,7 \mathrm{t}_{\mathrm{ka}} /$ ha. Tuloksista voitiin laskea myös käytännön puintitilanteessa saatu satoindeksi (siemensato/biomassan määrä), joka oli rypsillä 0,37 ja rapsilla 0,38, kun sängen osuutta (rypsi $21 \mathrm{~cm}$, rapsi $27 \mathrm{~cm}$ ) ei laskettu mukaan. Jos halutaan vähentää öljykasvien jääntitaimia seuraavina vuosina, puintitappioita pitäisi pystyä pienentämään esimerkiksi puimurin rakenteita muuttamalla, optimoimalla korjuuaikaa ja mahdollisesti keräämällä varsimassa kokonaisena talteen.

Simuloidussa tilanteessa, jossa rapsin siementä kylvettiin syksyllä 2004 viljan sängen päälle, siemenistä iti heti 14 - 18 \%. Taimettuvien rapsien määrä väheni jyrkästi seuraavina vuosina (2005-2007). Jääntikasveja havaittiin vähiten tavanomaisessa kyntöviljelyssä (Kuva 2). Kesannon ja suorakylvön välillä ei ollut suurta eroa. Vuonna 2007 alueella ei tavattu enää rapsin taimia. Vaikka tutkimus tehtiin vastapuidulla, käsittelemättömällä rapsin siemenellä, viljan sänki ei todennäköisesti vastannut olosuhteita, jotka vallitsevat rapsin puinnin jälkeen. Viereisellä rapsipellolla puinnin jälkeen itäneiden taimien määrä 
oli noin kaksi suurempi. Puinnissa lienee varissut huomattavasti suurempi määrä siementä kuin 63 kg/ha.

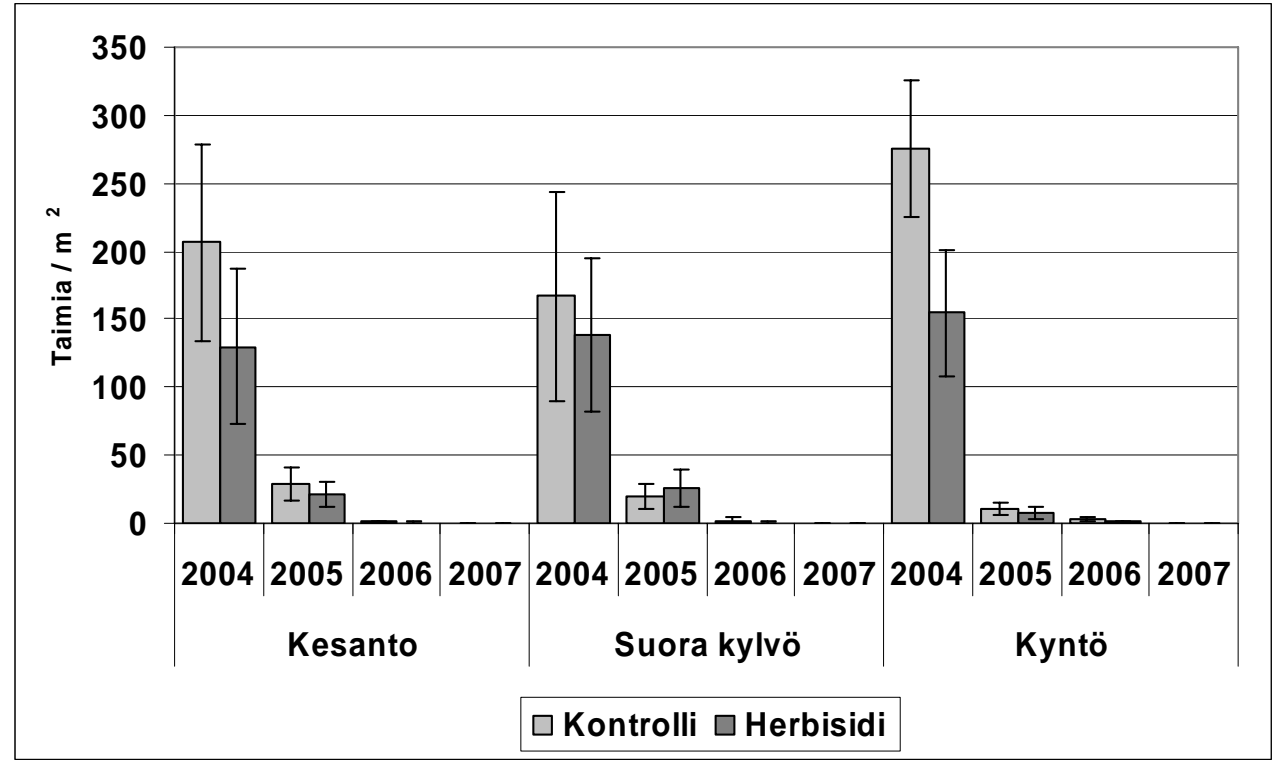

Kuva 2. Jääntikasvien taimettuminen eri viljelymenetelmiä käytettäessä. Alueelle syksyllä 2004 levitetty siemenmäärä $63 \mathrm{~kg} / \mathrm{ha}\left(1425 \mathrm{kpl} / \mathrm{m}^{2}\right)$. Jokioinen 2004-2007.

Rapsin jääntisiemenet säilyivät itämiskykyisinä pisimmän aikaa, kun ne olivat 10 tai $20 \mathrm{~cm}$ syvyydessä. Kolmen vuoden kuluttua $10 \%$ siemenistä oli vielä elossa (Kuva 3). Maanpinnalle jätetyissä verkkopusseissa vain muutama siemen oli enää elossa. Suuri osa rapsin ja rypsin korjuussa varisseista siemenistä iti heti varisemisen jälkeen maan pinnalla. Tämän vuoksi kaikki taimettumista edistävät toimenpiteet ovat tarpeen, sillä ne siemenet, jotka itävät syksyn aikana, eivät ole enää tuottamassa jääntikasveja seuraavina vuosina. Muokkaustoimenpiteiden lykkääminen mahdollisimman myöhään antaa aikaa taimettumiselle. Jos puintijäte silputaan paksuksi matoksi varisseiden siementen päälle, osa siemenistä saattaa jäädä taimettumatta valon puutteen vuoksi.

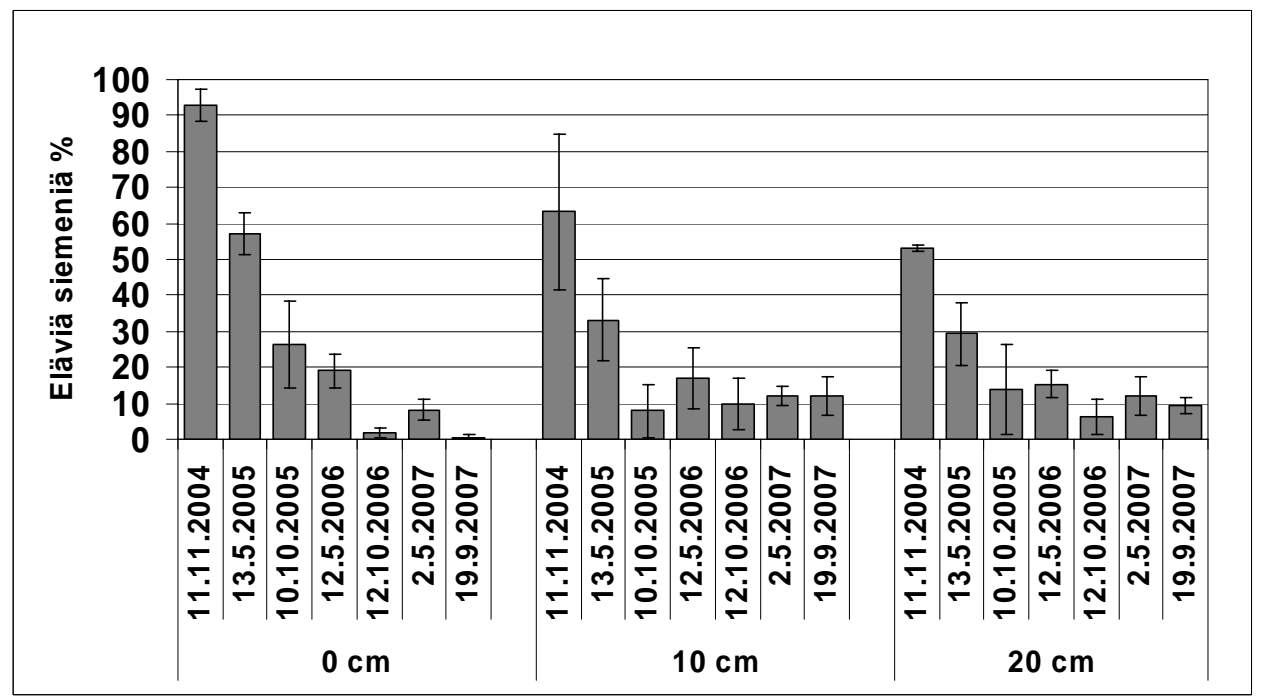

Kuva 3. Maassa 0, 10 ja 20 cm:n syvyydessä säilytettyjen siementen itävyys. Koe perustettu 5.10.2004 Jokioisille.

Rypsin ja rapsin jääntikasvit voitiin hävittää viljasta nykyisillä herbisibivalmisteilla (Taulukko 1). Edellytyksenä oli, että mahdolliset jääntikasvit olivat jo taimettuneet käsittelyhetkellä. Käsittelemättömän koejäsenen tulokset osoittivat, että kilpailukykyinen kevätvilja voi vähentää tehokkaasti öljykasvitaimien lukumäärää ja biomassaa. Kauran seassa öljykasvit pystyivät tuottamaan lituja, mutta siemenet eivät ehtineet kypsyä. Torjunta-aineruiskutukset tuhosivat kaikki taimettuneet öljykasvit. Kirpat ja 
rapsikuoriaiset vioittivat käsittelyn jälkeen taimettuneita öljykasveja. Käsittelyn jälkeen taimettuneita kasveja, eläviä kasveja löytyi enää vain Hedonal MCPA:lla käsitellyistä rypsi+kaura-ruuduista. Kilpaileva kevätvilja ja tehokas herbisidikäsittely hävittävät öljykasvien taimet, mutta käsittelyn jälkeen taimettuvat kasvit saattavat muodostua ongelmaksi.

Taulukko 1. Öljykasvien ja siementen lukumäärä ja biomassa neliömetriä kohden 10.9. puhtaassa kasvustossa ja kaura+öljykasvi -kasvustossa. Herb 1 = Ariane S, Herb 2 = Seos Express 50T+Hedonal MCPA, Herb $3=$ Hedonal MCPA. Jokioinen, 2007.

\begin{tabular}{|c|c|c|c|c|c|}
\hline Koejäsen & Öljykasvit/m² & Käsittelemätön & Herb 1 & Herb 2 & Herb 3 \\
\hline Rapsi & rapseja kpl & 144 & & & \\
\hline \multirow{7}{*}{ Rapsi + kaura } & siem kpl & 34448 & & & \\
\hline & siem g & 103 & & & \\
\hline & varret ja lidut g & 663 & & & \\
\hline & rapseja kpl & 99 & & & \\
\hline & siem kpl & 44 & & & \\
\hline & siem g & 0,004 & & & \\
\hline & varret ja lidut g & 22 & & & \\
\hline \multirow[t]{4}{*}{ Rypsi } & rypsejä kpl & 91 & & & \\
\hline & siem kpl & 31968 & & & \\
\hline & siem g & 72 & & & \\
\hline & varret ja lidut g & 320 & & & \\
\hline \multirow[t]{4}{*}{ Rypsi + kaura } & rypsejä kpl & 24 & & & 16 \\
\hline & siem kpl & 160 & & & 88 \\
\hline & siem g & 0,14 & & & 0,02 \\
\hline & varret ja lidut g & 2,10 & & & 0,82 \\
\hline
\end{tabular}

\section{Johtopäätökset}

Puintitappiot olivat suurin jääntisiementen lähde; rapsilla 5,2 \% ja rypsillä 4,5 \% sadosta, mikä tarkoittaa yli kymmenkertaista määrää kylvösiemeneen verrattuna. Puintitappioiden vähentämisellä ja edistämällä varisseiden siementen itämistä heti puinnin jälkeen saadaan jääntikasvien määrää vähennettyä. Siemenet säilyvät vähintään kolme vuotta itävinä $10-20 \mathrm{~cm}$ syvällä maassa ja ovat siten potentiaalinen ja pitkäaikainen jääntikasvien lähde. Vähintään viiden vuoden tauko öljykasvien viljelyssä on tarpeen jääntikasvien takiakin. Välivuosien aikana pellolla kannattaa viljellä esimerkiksi kevätviljaa, jonka seasta öljykasvien taimet pystytään torjumaan spektriltään monipuolisilla herbisideillä.

Ristikukkaisten öljykasvien GM-lajikkeiden mahdollinen tulo Suomeen saattaa aiheuttaa riskin tavanomaisten lajikkeiden viljelylle sekä luomutuotannolle. Erityisesti rapsin ja rypsin siementen variseminen puinnin yhteydessä, säilyminen maassa itävänä useita vuosia ja lajikkeiden dormanssiherkkyys voivat johtaa ei-toivotun geeniaineksen siirtymiseen, jos GM-lajikkeita aletaan viljellä rypsin pääviljelyalueilla.

\section{Kirjallisuus}

Crawley, M.J., Hails, R.S., Rees, M., Kohn, D. \& Buxton, J. 1993. Ecology of transgenic oilseed rape in natural habitats. Nature, 363: 620-623.

ISO 8210. Equipment for harvesting - Combine harvesters - Test procedure.

Hämet-Ahti, L., Suominen, J.,Ulvinen, T.\& Uotila, P. (toim.) (1998). Retkeilykasvio. Helsingin yliopisto, Kasvimuseo. Yliopistopaino, Helsinki, pp. 187-189.

Pahkala, K. 2003. Germination and establishment of spring sown oilseed crops. In: Hilmer Sørensen et al. (eds). Proceedings of the 11th International rapeseed congress, 6.-10. July 2003, Copenhagen, Danmark. p. 959-962.

Pahkala, K. \& Sankari, H. 2001. Seed loss as a result of pod shatter in spring rape and spring turnip rape in Finland. Agricultural and food science in Finland 10, 3: 209-216.

Salonen, J., Hyvönen, T. \& Jalli, H. 2001. Weeds in spring cereal fields in Finland - a third survey. Agricultural and Food Science, p. 347-364.

Woolley, J.T. \& Stoller, E.W. 1978: Light penetration and light-induced seed germination in soil. Plant Physiology 61: 597-600. 